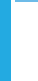

\title{
Prolactin receptor antagonism uncouples lipids from atherosclerosis susceptibility
}

\author{
Ronald J van der Sluis, Tim van den Aardweg, Anne Q Reuwer ${ }^{1}$, Marcel T Twickler ${ }^{2}$, \\ Florence Boutillon ${ }^{3}$, Miranda Van Eck, Vincent Goffin ${ }^{3, *}$ and Menno Hoekstra* \\ Division of Biopharmaceutics, Gorlaeus Laboratories, Leiden Academic Centre for Drug Research, \\ Einsteinweg 55, 2333CC Leiden, The Netherlands \\ ${ }^{1}$ Laboratory for Microbiology and Infection Control, Amphia Hospital, Breda, The Netherlands \\ ${ }^{2}$ Department Endocrinology, Diabetology and Metabolic Diseases, Antwerp University Hospital, Antwerp, Belgium \\ ${ }^{3}$ Inserm, Unit 1151,Prolactin/Growth Hormone Pathophysiology Laboratory, Faculty of Medicine, \\ Institut Necker Enfants Malades (INEM), University Paris Descartes, Sorbonne Paris Cité, Paris, France \\ *(V Goffin and M Hoekstra contributed equally to this work)
}

Correspondence should be addressed to M Hoekstra

Email

hoekstra@lacdr.leidenuniv.nl

\begin{abstract}
The pituitary-derived hormone prolactin has been suggested to stimulate the development of atherosclerosis and cardiovascular disease through its effects on metabolism and inflammation. In this study, we aimed to challenge the hypothesis that inhibition of prolactin function may beneficially affect atherosclerosis burden. Hereto, atherosclerosissusceptible LDL receptor ( $L d l r$ ) knockout mice were transplanted with bone marrow from transgenic mice expressing the pure prolactin receptor antagonist Del1-9-G129R-hPRL or their non-transgenic littermates as control. Recipient mice expressing Del1-9-G129R-hPRL exhibited a decrease in plasma cholesterol levels $(-29 \% ; P<0.05)$ upon feeding a Westerntype diet (WTD), which could be attributed to a marked decrease $(-47 \% ; P<0.01)$ in the amount of cholesterol esters associated with pro-atherogenic lipoproteins VLDL/LDL. By contrast, Del1-9-G129R-hPRL-expressing mice did not display any change in the susceptibility for atherosclerosis after 12 weeks of WTD feeding. Both the absolute atherosclerotic lesion size $\left(223 \pm 33 \times 10^{3} \mu \mathrm{m}^{2}\right.$ for Del1-9-G129R-hPRL vs $259 \pm 32 \times 10^{3} \mu \mathrm{m}^{2}$ for controls) and the lesional macrophage and collagen contents were not different between the two groups of bone marrow recipients. Importantly, Del1-9-G129R-hPRL exposure increased levels of circulating neutrophils $(+91 \% ; P<0.05)$, lymphocytes $(+55 \%$; $P<0.05)$, and monocytes $(+43 \% ; P<0.05)$, resulting in a $49 \%$ higher $(P<0.01)$ total blood leukocyte count. In conclusion, we have shown that prolactin receptor signaling inhibition uncouples the plasma atherogenic index from atherosclerosis susceptibility in Ld/r knockout mice. Despite an associated decrease in VLDL/LDL cholesterol levels, application of the prolactin receptor antagonist Del1-9-G129R-hPRL does not alter the susceptibility for initial development of atherosclerotic lesions probably due to the parallel increase in circulating leukocyte concentrations.
\end{abstract}

\section{Key Words}

- prolactin receptor

- Del1-9-G129R-hPRL

- lipoprotein

- atherosclerosis

- mouse model
Journal of Endocrinology (2014) 222, 341-350 http://joe.endocrinology-journals.org DOI: 10.1530/JOE-14-0343
C 2014 Society for Endocrinology Printed in Great Britain
Published by Bioscientifica Ltd. 


\section{Introduction}

Cardiovascular disease represents a major source of mortality in the Western world. Atherosclerosis, i.e., narrowing of the arteries as a result of lipid deposition, is the primary underlying biological cause of cardiovascular disease. High plasma cholesterol levels are an established risk factor for the development of atherosclerosis. Druginduced lowering and normalization of cholesterol levels are therefore the primary therapy for patients at risk of cardiovascular disease. However, traditional cholesterollowering treatments only reduce the incidence of cardiovascular disease complications by $20-30 \%$ (Cholesterol Treatment Trialists' (CTT) Collaborators et al. 2012). Thus, there remains a clear need for the development of alternative anti-atherogenic therapies.

Recent clinical evidence has identified the pituitaryderived hormone prolactin as a potential novel target to treat patients at risk of cardiovascular disease. Hyperprolactinemic subjects harboring a prolactin-secreting pituitary adenoma (prolactinoma) also display an increase in carotid intima media thickness (IMT), a sub-clinical marker for atherosclerosis (Arslan et al. 2014, Jiang et al. 2014). In these patients, prolactin levels independently predict the extent of IMT (Jiang et al. 2014). Furthermore, prolactin levels in post-menopausal women correlate with the HeartScore, a composite index that predicts 10-year cardiovascular mortality by taking into account age, sex, systolic blood pressure, total cholesterol, and smoking status (Georgiopoulos et al. 2009). Importantly, relatively high prolactin levels are also associated with a sexindependent increase in all the cause and cardiovascular disease-specific mortality rate in the general population (Haring et al. 2014).

In the current study, we aimed to challenge the hypothesis that inhibition of prolactin function may beneficially affect atherosclerosis burden. Dopamine receptor agonists such as bromocriptine effectively lower prolactin secretion by the pituitary and are the primary treatment option for prolactinoma patients ( $\mathrm{Wu}$ et al. 2006, Yarman et al. 2012). However, these agents may also theoretically affect atherosclerosis susceptibility by altering dopamine action locally in the atherosclerotic plaque, as dopamine receptors have been detected in both smooth muscle cells (Zeng et al. 2004, Li et al. 2008) and different types of leukocytes (McKenna et al. 2002). The prolactin receptor antagonist Del1-9-G129R-hPRL is an inactive prolactin variant that efficiently competes with endogenous prolactin for binding to the prolactin receptor (Bernichtein et al. 2003), leading to a disruption of normal prolactin action in vivo (Rouet et al. 2010). To specifically show the impact of prolactin function inhibition on atherogenesis, we induced the expression of the prolactin receptor antagonist Del1-9-G129R-hPRL in atherosclerosissusceptible LDL receptor ( $L d l r)$ knockout mice.

\section{Materials and methods}

\section{Mice and bone marrow transplantation}

Animal experiments were approved by the Ethics Committee for Animal Experiments of Leiden University and carried out at the Gorlaeus Laboratories of the Leiden/Amsterdam Center for Drug Research in accordance with the National Laws and the Directive 2010/63/EU of the European Parliament.

Transgenic mice expressing the Del1-9-G129R-hPRL gene under control of the ubiquitous metallothionein I promoter (Rouet et al. 2010) and non-transgenic littermate controls were bred at Inserm (Paris, France) and subsequently used as donors for bone marrow transplantation. Genetically hyperlipidemic homozygous C57BL/6J Ldlr knockout mice (Ishibashi et al. 1993) were obtained from The Jackson Laboratory (Bar Harbor, ME, USA) as mating pairs and bred at the Gorlaeus Laboratories, Leiden, The Netherlands. Age-matched Ldlr knockout mice served as bone marrow recipients. As prolactin can influence the secretion of female-specific hormones (i.e., estrogens) and vice versa, male mice were chosen as recipients to minimize the covariable effects of other hormones on atherosclerosis. Lethally irradiated recipients $(2 \times 4.5 \mathrm{~Gy} ; 11-12$ mice per group) received $5 \times 10^{6}$ bone marrow cells by i.v. injection into the tail vein 1 day after irradiation. After a recovery period of 8 weeks on a regular chow diet containing $4.3 \%$ fat and no cholesterol, the animals were challenged with a Western-type diet (WTD; 0.25\% cholesterol and 15\% cocoa butter) for 12 weeks to induce atherosclerotic lesion development. At 20 weeks after transplantation, mice were anaesthetized by s.c. injection with a mixture of $70 \mathrm{mg} / \mathrm{kg}$ body weight of xylazine, $1.8 \mathrm{mg} / \mathrm{kg}$ bodyweight of atropine, and $350 \mathrm{mg} / \mathrm{kg}$ body weight of ketamine. Animals were subsequently killed by cervical dislocation.

\section{Genotyping}

DNA was extracted from the bone marrow and spleen of different recipient mice. Genotyping was performed essentially as described previously (Rouet et al. 2010).

Published by Bioscientifica Ltd. 


\section{Analysis of gene expression by real-time quantitative PCR}

Quantitative gene expression analysis on snap-frozen liver and spleen was performed as described previously (Hoekstra et al. 2003). Total RNA was isolated according to Chomczynski \& Sacchi (1987) and reverse transcribed using RevertAid reverse transcriptase. Gene expression analysis was performed using real-time SYBR Green Technology (Eurogentec, Seraing, Belgium). Primers were validated for identical efficiencies and the primer sequences are given in Table 1. Beta-actin (Actb), ATP synthase, $\mathrm{H}+$ transporting, mitochondrial F0 complex, subunit F6 (Atp5j), beta-glucuronidase (Gusb), and acidic ribosomal phosphoprotein P0 (36B4 (RplpO)) were used as the standard housekeeping genes.

\section{Plasma measurements}

Plasma prolactin levels were measured using a mouse prolactin-specific ELISA kit (Calbiotech, Inc., Spring Valley, CA, USA). Corticosterone levels were determined using the CORTICOSTERONE Double Antibody ${ }^{125}$ I RIA Kit obtained from MP Biomedicals (Irvine, CA, USA). Murine monocyte chemoattractant protein 1 (MCP1 (CCL2)) levels were assayed in plasma using a MCP-1 instant ELISA kit (eBioscience, Hatfield, UK) according to the manufacturer's instructions. Concentrations of free and total cholesterol, cholesterol esters, and triglycerides were determined using enzymatic colorimetric assays (Roche Diagnostics). The distribution over the different lipoproteins was analyzed by fractionation of $30 \mu \mathrm{l}$ of plasma of each mouse using a Superose 6 column $(3.2 \times$ $300 \mathrm{~mm}$, Smart-system, Pharmacia).

\section{Histological analysis of the aortic root}

To analyze the development of atherosclerosis at the aortic root, the arterial tree was perfused in situ with PBS $(100 \mathrm{mmHg})$ for $10 \mathrm{~min}$ via a cannula in the left ventricular apex. The heart along with the aortic root were excised and stored in 3.7\% neutral buffered formalin (Formal-fixx; Shandon Scientific Ltd, Runcorn, UK). Serial sections $(10 \mu \mathrm{m})$ of the aortic root were cut using a Leica CM3050S cryostat. The atherosclerotic lesion areas in Oil red O-stained cryostat sections of the aortic root were quantified using the Leica image analysis system, consisting of a Leica DMRE microscope coupled to a video camera and the Leica Qwin Imaging software (Leica Ltd, Cambridge, UK). Mean lesion area (in $\mu \mathrm{m}^{2}$ ) was calculated from $\geq 5$ consecutive Oil red O-stained sections of the aortic root, starting at the appearance of the tricuspid valves. Collagen content of the lesions was determined after Masson's Trichrome staining (Sigma Diagnostics). Sections were stained immunohistochemically for the presence of macrophages using a MOMA-2 antibody (dilution 1:50; Serotec Ltd, Oxford, UK) respectively. A goat anti-rat antibody coupled to HRP (1:100) (Dako, Glostrup, Denmark) was used as a secondary antibody and Nova red substrate (Vector Laboratories, Burlingame, CA, USA) was used for visualization of HRP.

\section{Hematological analysis}

Total leukocyte numbers as well as the absolute number of neutrophils, monocytes, and lymphocytes in whole blood samples with EDTA anticoagulant obtained at the time of killing were routinely measured using an automated

Table 1 Primers used for quantitative real-time PCR

\begin{tabular}{|c|c|c|}
\hline Genes & Accession & Forward primer \\
\hline $36 B 4$ & NM007475 & CTGAGTACACCTTCCCACTTACTGA \\
\hline Actb & NM007393 & AACCGTGAAAAGATGACCCAGAT \\
\hline Atp5j & NM016755 & CAGGGCCGGAAGTAGAACGG \\
\hline Dgat1 & NM010046 & GGTGCCCTGACAGAGCAGAT \\
\hline Fasn & NM007988 & GGCGGCACCTATGGCGAGG \\
\hline Gusb & NM010368 & TATGGAGCAGACGCAATCCCAG \\
\hline$H I$ & NM008280 & AGAGCCTACTTTTACCATGTCGCT \\
\hline Ifn $\gamma$ & NM008337 & ATAACTATTTTAAACTCAAGTGGCATAGATGT \\
\hline$L p l$ & NM008509 & CCCCTAGACAACGTCCACCTC \\
\hline Lrp1 & NM008512 & CTTCTGGTGGCTGGCGTGGTG \\
\hline Mcp1 & NM011333 & CTGAAGCCAGCTCTCTCTTCCTC \\
\hline Scd1 & NM009127 & TACTACAAGCCCGGCCTCC \\
\hline$S R B I$ & NM016741 & AAACAGGGAAGATCGAGCCAGTAG \\
\hline $\operatorname{Tnf} \alpha$ & X02611 & GCCTCTTCTCATTCCTGCTTGTG \\
\hline
\end{tabular}

\section{Reverse primer}

CGACTCTTCCTTTGCTTCAGCTTT

CACAGCCTGGATGGCTACGTA

AAGGACAGAGGAGAGCCTGAAGA

CAGTAAGGCCACAGCTGCTG

CTCCAGCAGTGTGCGGTGGTC

AGCTCTCCGACCACGTATTCTTTAC

CGGGATGTCTTTGTCCAGTGTG

TCT GGC TCT GCA GGA TTT TCA

TGGGGGCTTCTGCATACTCAAA

CATCCGCTGGTGCTGGAAGCC

CCTCAATGAGTAGCAGCAGGTGA

CAGCAGTACCAGGGCACCA

CGTAGTGAAGAACCTGGGGCAT

ATGATCTGAGTGTGAGGGTCTGG 
A
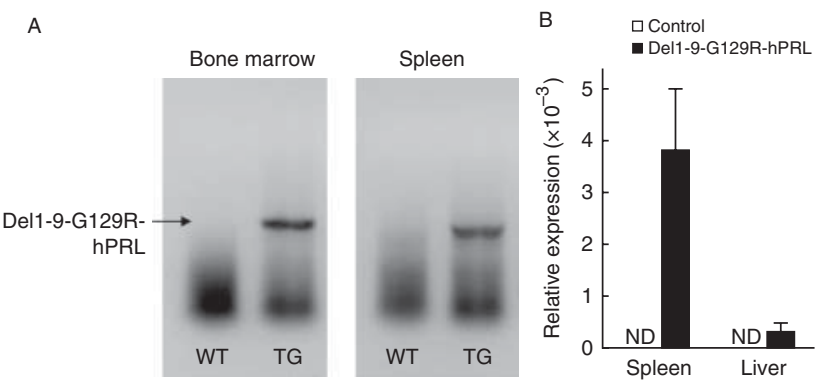

Figure 1

Successful introduction of the prolactin antagonist Del1-9-G129R-hPRL by bone marrow transplantation. PCR on genomic DNA of bone marrow and spleens (A) and gene expression analysis on livers and spleens (B) isolated from LDL receptor knockout mice transplanted with bone marrow from Del1-9-G129R-hPRL transgenic (TG/Del1-9-G129R-hPRL) mice and their non-transgenic controls (WT/Control) at 20 weeks after bone marrow transplantation. Data in (B) are expressed as means \pm s.E.M. of 5-6 mice per group. ND, not detected.

Sysmex XT-2000iV Veterinary Hematology analyzer (Sysmex Corporation, Etten-Leur, The Netherlands). Glucose levels were measured in blood drops using ACCU-CHEK compact strips.

\section{Statistical analysis}

Statistical analysis was performed using the Graphpad Instat software (San Diego, CA, USA, http://www.graphpad.com). Normality of the experimental groups was confirmed using the method of Kolmogorov and Smirnov. The significance of differences was calculated using a two-tailed unpaired $t$-test. Probability values $<0.05$ were considered significant.

\section{Results}

\section{Bone marrow transplantation induces detectable expression of Del1-9-G129R-hPRL}

Our previous studies in which we transplanted mice with bone marrow from transgenic/knockout mice have shown the value of bone marrow transplantation to uncover the effect of secreted peptides/proteins on atherosclerosis susceptibility (Van Eck et al. 1997, 2007, Vikstedt et al. 2007). We therefore transplanted lethally irradiated Ldlr knockout mice with bone marrow from either Del1-9-G129R-hPRL transgenic mice or their nontransgenic littermate controls to induce long-term (constitutive) expression of the prolactin receptor antagonist and show the potential of prolactin receptor antagonism to reduce the atherosclerosis risk. At the time of killing, genotyping was performed on bone marrow and spleen isolated to assess that the Del1-9-G129R-hPRL sequence was present only in the DNA of mice transplanted with the transgenic donor bone marrow (Fig. 1A). WT bone marrow recipients showed undetectable gene expression of Del1-9-G129R-hPRL (Ct $\geq 40)$ in their liver and spleen, two tissues rich in bone marrowderived cells. By contrast, mRNA expression of Del1-9G129R- $h P R L$ could be readily detected in spleens $(\mathrm{Ct}=30.1 \pm 0.5 ; n=6)$ and, to a lesser extent, in livers $(\mathrm{Ct}=35.2 \pm 2.0 ; n=5)$ of transgenic bone marrow recipients (Fig. 1B). Endogenous (mouse) prolactin levels in plasma were not different between the two experimental groups (Table 1). Owing to the mutations harbored by Del1-9-G129R-hPRL to convert prolactin into a functional antagonist, the latter is not recognized by human prolactin immunoassays that have been tested thus far (data not shown). As a sensitive assay to detect this antagonist remains yet to be developed, we were unable to determine the actual levels of Del1-9-G129R-hPRL protein in the plasma of the bone marrow recipient mice.

\section{Del1-9-G129R-hPRL expression in bone marrow is associated with a decrease in the plasma atherogenic index}

Prolactinoma patients suffer from dyslipidemia. Lowering their circulating prolactin levels using dopamine agonists was shown to decrease plasma LDL cholesterol levels (Fahy et al. 1999, Berinder et al. 2011). To determine whether such a relation between prolactin signaling and cholesterol levels also existed in our experimental mouse
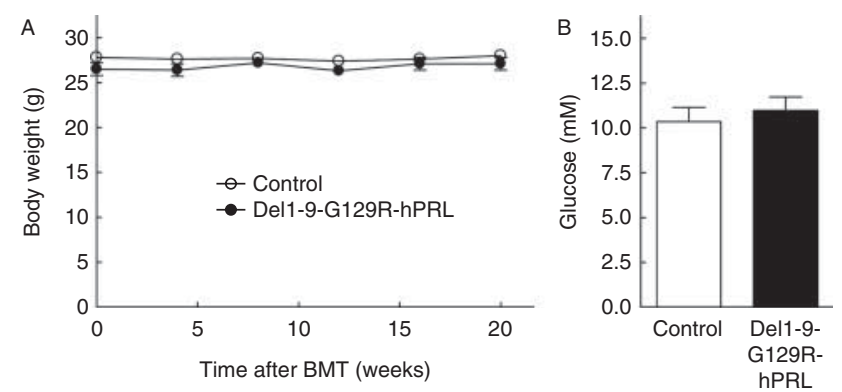

\section{Figure 2}

Body weight profile and blood glucose levels in Del1-9-G129R-hPRL transgenic bone marrow-transplanted LDL receptor knockout mice and their non-transgenic littermate bone marrow-transplanted controls. Body weight was recorded at the indicated points after the bone marrow transplantation (BMT; A). Glucose levels were determined in blood collected from 12-week Western-type-diet-fed mice after $4 \mathrm{~h}$ of fasting (B). Data are expressed as means \pm s.E.M. of 11-12 mice per group.

Published by Bioscientifica Ltd. 
Table 2 Effect of Del1-9-G129R-hPRL expression on plasma parameters. Data are expressed as means \pm s.E.M.

\begin{tabular}{|c|c|c|c|}
\hline & $\begin{array}{l}\text { Control } \\
(n=11)\end{array}$ & $\begin{array}{l}\text { Del1-9-G129R- } \\
\text { hPRL }(n=12)\end{array}$ & $P$ value \\
\hline \multicolumn{4}{|l|}{ Chow diet } \\
\hline $\begin{array}{l}\text { Triglycerides } \\
\text { (mg/dl) }\end{array}$ & $162 \pm 9$ & $155 \pm 7$ & 0.55 \\
\hline $\begin{array}{l}\text { Total cholesterol } \\
(\mathrm{mg} / \mathrm{dl})\end{array}$ & $250 \pm 10$ & $252 \pm 7$ & 0.89 \\
\hline \multicolumn{4}{|l|}{ Western-type diet } \\
\hline $\begin{array}{l}\text { Triglycerides } \\
\text { (mg/dl) }\end{array}$ & $498 \pm 67$ & $457 \pm 57$ & 0.64 \\
\hline $\begin{array}{l}\text { Total cholesterol } \\
(\mathrm{mg} / \mathrm{dl})\end{array}$ & $1788 \pm 173$ & $1262 \pm 164$ & 0.038 \\
\hline $\begin{array}{l}\text { Free cholesterol } \\
(\mathrm{mg} / \mathrm{dl})\end{array}$ & $796 \pm 67$ & $642 \pm 52$ & 0.082 \\
\hline $\begin{array}{l}\text { Cholesterol esters } \\
(\mathrm{mg} / \mathrm{dl})\end{array}$ & $1676 \pm 193$ & $891 \pm 133$ & 0.003 \\
\hline Prolactin (OD) & $0.091 \pm 0.008$ & $0.101 \pm 0.006$ & 0.35 \\
\hline
\end{tabular}

model, we measured plasma lipid levels in bone marrow-transplanted mice both after 8 weeks recovery on a chow diet and after subsequent WTD feeding for 12 weeks. No apparent changes in food consumption were noted. In accordance with similar food intake, body weights as well as blood glucose levels were identical in the two transplant groups (Fig. 2). No difference in plasma total cholesterol or triglyceride levels was noted with respect to bone marrow genotype while feeding a chow diet (Table 2). By contrast, under WTD feeding conditions, plasma total cholesterol levels were significantly lowered $(-29 \% ; P<0.05)$ in Del19-G129R-hPRL bone marrow-transplanted mice when compared with WT bone marrow recipients (Table 2). Triglyceride levels were also not different between the two groups upon feeding the WTD, indicative of a similar intestinal lipid absorption rate. Further specification of the effect on plasma cholesterol levels indicated that the decrease in total cholesterol levels observed on the WTD was mainly due to a marked reduction $(47 \%, P<0.01)$ in the plasma cholesterol ester concentration, as free cholesterol levels only tended to decrease $(-19 \%$; $P=0.08$ ). Lipoprotein distribution analysis on pooled plasma revealed that Del1-9-G129R-hPRL exposure reduced the atherogenic index of the plasma compartment. The level of cholesterol associated with proatherogenic lipoproteins VLDL and LDL was decreased, while anti-atherogenic HDL cholesterol levels were similar between the two groups of mice (Fig. 3). The decrease in VLDL/LDL cholesterol levels could not be attributed to changes in hepatic expression levels of key lipogenic genes (Fasn, Dgat1, and Scd1). In addition, relative mRNA expression levels of proteins associated with the catabolism of triglyceride-rich VLDL particles (LPL and HL) and the uptake of smaller sized LDL particles by the liver (LRP1 (LIPC) and SRBI (SCARB1)) were not significantly different upon Del1-9-G129R-hPRL exposure (Table 3).

\section{Del1-9-G129R-hPRL expression in bone marrow does not affect the initial development of atherosclerotic lesions}

Mice transplanted with WT bone marrow developed macrophage-rich early atherosclerotic lesions in the aortic root, which were almost devoid of collagen $(<2 \%$; Fig. 4$)$ in response to 12 weeks of WTD feeding. In accordance with an initial stage of lesion development, no atherosclerotic plaques (white lipid deposits) were microscopically visible in the aortic arch and descending aorta in either transplant groups upon killing. Strikingly, the size of the atherosclerotic lesions in the aortic root was not different in Del1-9-G129R-hPRL recipients $(n=10$, mean lesion size: $223 \pm 33 \times 10^{3} \mu \mathrm{m}^{2}$ ) when compared with the WT bone marrow-transplanted mice $\left(n=11,259 \pm 32 \times 10^{3} \mu \mathrm{m}^{2}\right)$. Lesional macrophage and collagen contents did not differ
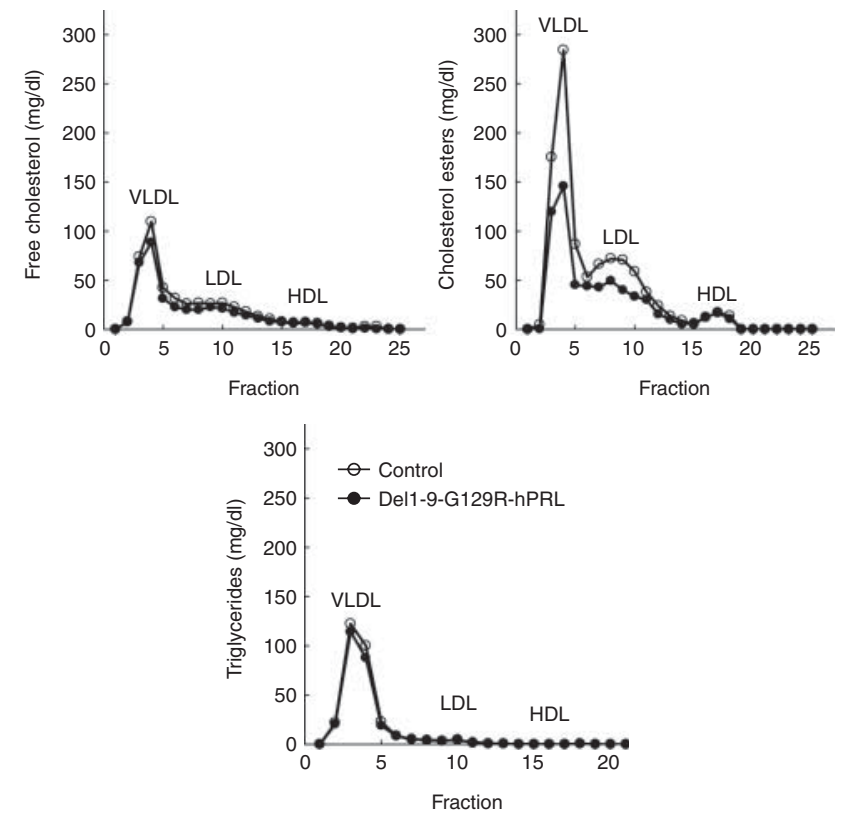

Figure 3

Lipoprotein profiles of Del1-9-G129R-hPRL transgenic bone marrowtransplanted LDL receptor knockout mice and their non-transgenic littermate-transplanted controls. Pooled plasma, collected in the ad libitum fed state after 12 weeks of WTD feeding, was subjected to fast performance liquid chromatography. Distribution of free cholesterol, cholesterol esters, and triglycerides over the different lipoprotein fractions was determined enzymatically.

Published by Bioscientifica Ltd. 
Table 3 Effect of Del1-9-G129R-hPRL expression on hepatic gene expression levels. Given the high sensitivity of the quantitative real-time PCR method, five out of six livers were randomly chosen from the two groups of mice for biochemical analysis. Data are expressed as fold change compared with control values and represent means \pm s.E.M.

\begin{tabular}{|c|c|c|c|}
\hline & $\begin{array}{c}\text { Control } \\
(n=6)\end{array}$ & $\begin{array}{l}\text { Del1-9-G129R- } \\
\text { hPRL }(n=5)\end{array}$ & $P$ value \\
\hline Dgat1 & $1.00 \pm 0.11$ & $1.27 \pm 0.15$ & 0.22 \\
\hline Fasn & $1.00 \pm 0.18$ & $1.13 \pm 0.14$ & 0.49 \\
\hline $\mathrm{HI}$ & $1.00 \pm 0.09$ & $1.04 \pm 0.10$ & 0.75 \\
\hline$L p l$ & $1.00 \pm 0.12$ & $1.30 \pm 0.09$ & 0.07 \\
\hline Lrp1 & $1.00 \pm 0.14$ & $0.96 \pm 0.09$ & 1.00 \\
\hline Scd1 1 & $1.00 \pm 0.17$ & $0.97 \pm 0.32$ & 0.66 \\
\hline SCARB 1 & $1.00 \pm 0.25$ & $0.91 \pm 0.19$ & 0.94 \\
\hline
\end{tabular}

between the two experimental groups (Fig. 4), which suggests that the stability of the atherosclerotic lesions was also not affected by prolactin receptor antagonism. It thus appears that the lowered atherogenic index in Del19-G129R-hPRL bone marrow-transplanted mice does not translate into an altered susceptibility for the development of initial atherosclerotic lesions.

\section{Del1-9-G129R-hPRL expression in bone marrow is associated with increased blood leukocyte counts}

As inflammation is a key feature in the pathogenesis of atherosclerosis, we determined whether introduction of Del1-9-G129R-hPRL in our Ldlr knockout mice was associated with a change in immune status. Splenic mRNA expression levels of the pro-inflammatory cytokines $M c p 1$, tumor necrosis factor alpha $(\operatorname{Tnf} \alpha(T n f))$, and interferon gamma (Ifn $\gamma(I f n g)$ ) were not significantly altered by Del1-9-G129R-hPRL treatment (Table 4). In parallel, plasma protein levels of MCP1 were not notably different (Fig. 5A). By contrast, Del1-9-G129R-hPRL application induced a significant change in the concentration of circulating white blood cells. Total leukocyte numbers were $49 \%$ higher $(P<0.01)$ in Del1-9-G129R-hPRL bone marrow recipients, which could be attributed to an increase in concentrations of neutrophils $(+91 \% ; P<0.05)$, lymphocytes $(+55 \% ; P<0.05)$, and monocytes $(+43 \%$; $P<0.05$ ) (Fig. 6). Previous studies have suggested a possible effect of prolactin on the secretion of anti-inflammatory glucocorticoids by the adrenals (Chang et al. 1999, Lo \& Wang 2003, Dugan et al. 2007, Jaroenporn et al. 2007). However, plasma levels of corticosterone, the primary glucocorticoid circulating in mice, were not different between the two treatment groups (Fig. 5B).

\section{Discussion}

As a clinical association between prolactin levels and the risk of cardiovascular disease exists, we evaluated the impact of treatment with the prolactin receptor antagonist Del1-9-G129R-hPRL on atherosclerosis susceptibility in the commonly used $L d l r$ knockout disease mouse model. Bone marrow-derived Del1-9-G129R-hPRL lowered the atherogenic index of the plasma compartment as measured by a decrease in VLDL/LDL cholesterol levels. Although it is recognized that lowering the prolactin levels by bromocriptine treatment executes a beneficial impact on plasma cholesterol levels in hyperprolactinemic patients (Fahy et al. 1999, Berinder et al. 2011); to our knowledge this drug has not been tested in the experimental mouse model used in this study. Our findings suggest that lowering prolactin signaling by receptor targeting may constitute an alternative therapeutic approach to lower the plasma levels of pro-atherogenic lipoproteins also in the general normoprolactinemic population.

Effective retrospective analysis of the relation between plasma lipid parameters and atherosclerosis susceptibility by VanderLaan et al. (2009) has indicated that, in Ldlr knockout mice, VLDL cholesterol levels and the non-HDL cholesterol to HDL cholesterol ratio served as the two best predictors of the aortic root atherosclerosis extent.
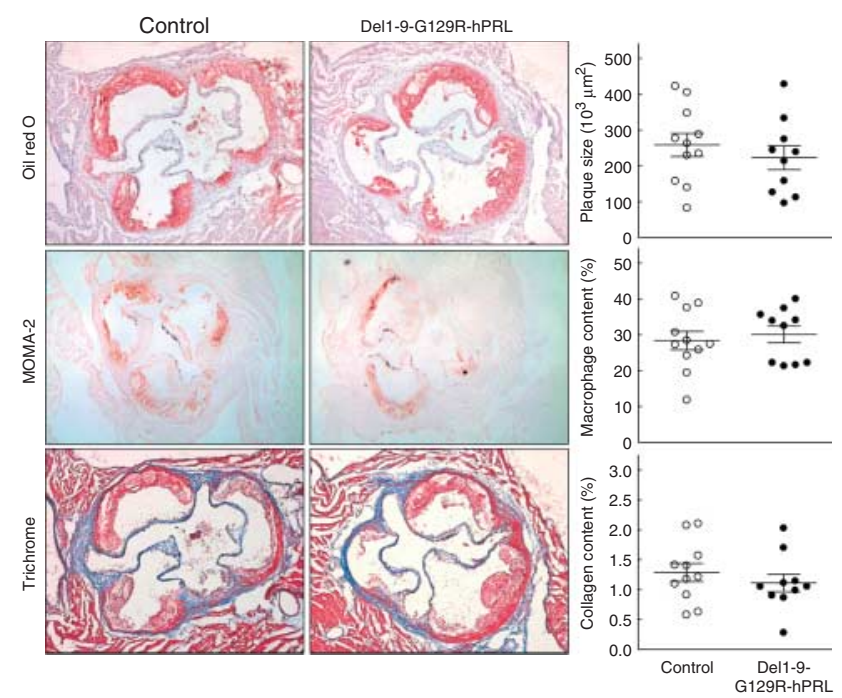

\section{Figure 4}

Analysis of atherosclerosis in the aortic root of bone marrow-transplanted LDL receptor knockout mice after 12 weeks of WTD feeding. Sections of the aortic root area were stained with Oil red $\mathrm{O}$ to visualize the total lesion area. MOMA-2 and trichrome stainings were used to show the presence of macrophages (red) and collagen (blue) respectively. Bullets in the graphs on the right represent the values of individual mice, while horizontal lines indicate the group averages \pm s.E.M.

Published by Bioscientifica Ltd. 
Table 4 Effect of Del1-9-G129R-hPRL expression on splenic gene expression levels. Given the high sensitivity of the quantitative real-time PCR method, six spleens were randomly chosen from the two groups of mice for biochemical analysis. Data are expressed as fold change compared with control values and represent means \pm s.E.M.

\begin{tabular}{|c|c|c|c|}
\hline & $\begin{array}{c}\text { Control } \\
(n=6)\end{array}$ & $\begin{array}{l}\text { Del1-9-G129R-hPRL } \\
\qquad(n=6)\end{array}$ & $P$ value \\
\hline Mcp1 & $1.00 \pm 0.12$ & $1.11 \pm 0.13$ & 0.63 \\
\hline $\operatorname{Tnf} \alpha$ & $1.00 \pm 0.39$ & $0.58 \pm 0.08$ & 0.63 \\
\hline Ifn $\gamma$ & $1.00 \pm 0.20$ & $1.15 \pm 0.24$ & 0.74 \\
\hline
\end{tabular}

Strikingly, the lowered VLDL/LDL cholesterol levels in the context of unchanged HDL cholesterol levels associated with Del1-9-G129R-hPRL treatment did not translate into a lower susceptibility for the development of atherosclerotic lesions. An apparent discrepancy between VLDL cholesterol levels and the extent of atherosclerosis thus exists in the Ldlr knockout mice model in our current experimental setting.

Blood leukocyte concentrations were markedly increased in Del1-9-G129R-hPRL bone marrow recipients when compared with Ldlr knockout mice transplanted with WT bone marrow. Importantly, multiple clinical studies have indicated that higher blood leukocyte numbers are an independent risk factor for cardiovascular disease (Tong et al. 2004, Jee et al. 2005, Twig et al. 2012, Hou et al. 2013). Thus, we hypothesize that the pro-atherogenic increase in leukocyte counts may balance the beneficial effect of Del1-9-G129R-hPRL-induced cholesterol lowering on atherosclerosis outcome.

We attempted to understand the mechanism by which the pure PRLR antagonist could increase leukocyte populations. Given that we used a bone marrow transplantation approach in which recipient mice are provided with the immune system of donor mice, a non-specific inflammatory (host vs graft) response to the antagonist can be excluded, in particular in light of the effective repopulation of leukocyte-rich organs such as the spleen. It is therefore assumed that the effect on leukocyte populations can directly be attributed to the prolactin receptor antagonism.

MCP1, the ligand for the CC-chemokine receptor CCR2, drives the accumulation of monocytes in the arterial sub-endothelial space. In accordance with an essential role for the MCP1/CCR2 axis in the development of atherosclerotic lesions, disruption of either MCP1 or CCR2 function lowers the extent of atherosclerosis in Ldlr knockout mice (Gu et al. 1998) as well as in atherosclerosis-susceptible Apoe knockout mice (Boring et al. 1998, Ni et al. 2001). As no changes in the plasma levels of MCP1 were noted, we anticipate that an increased mobilization of cells from bone marrow does not represent the underlying cause of the leukocytosis observed in Del1-9-G129R-hPRL-expressing mice.

Endogenous glucocorticoids, i.e., corticosterone in rodents and cortisol in humans, are some of the most potent immunosuppressive molecules as they inhibit the proliferation of lymphocytes and induce cell death in multiple white blood cell lineages. Accordingly, disruption of the endogenous glucocorticoid function through adrenalectomy was shown to be associated with an increased blood leukocyte concentration both in normolipidemic WT mice and Ldlr knockout and Apoe knockout hyperlipidemic mice (van der Sluis et al. 2012, Hoekstra et al. 2013). In our study, we failed to observe a change in plasma corticosterone levels between the two groups of transplanted mice at the time of killing, which does not argue for a major role for the glucocorticoid system.

In mice, the majority of circulating white blood cells as well as all lymphoid tissues express the prolactin receptor (Dardenne et al. 1994, Touraine \& Kelly 1995). Of note, PRLR protein expression has also been detected on macrophages locally within human atherosclerotic lesions (Reuwer et al. 2011). Thus, prolactin can also directly modulate the immune function. Although total
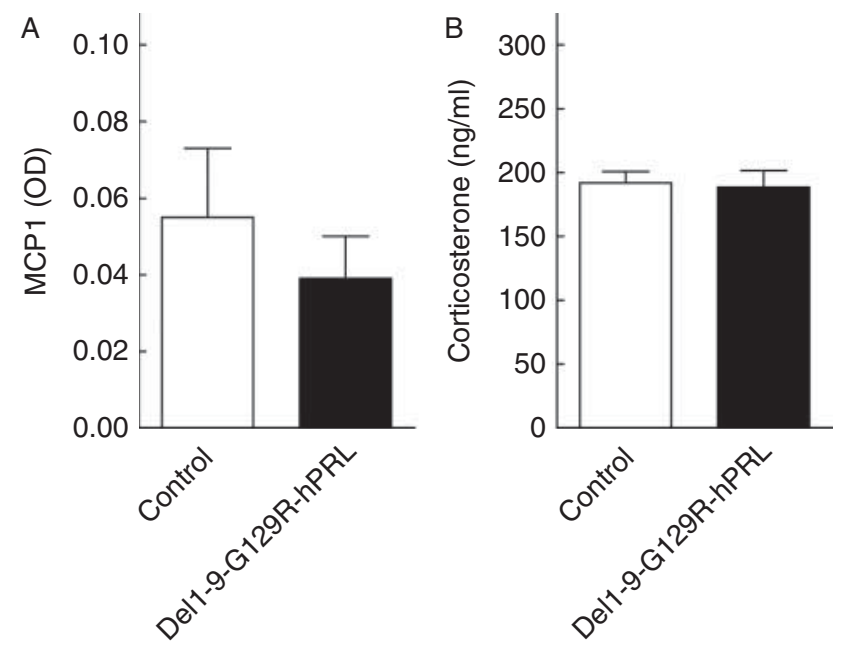

\section{Figure 5}

Plasma levels of (A) MCP1 and (B) corticosterone in Del1-9-G129R-hPRL transgenic bone marrow-transplanted LDL receptor knockout mice and their non-transgenic littermate-transplanted controls. Plasma samples were collected in the ad libitum fed state after 12 weeks of WTD feeding. Data are expressed as means \pm S.E.M. of six (MCP1) and 11-12 (corticosterone) mice per group.

Published by Bioscientifica Ltd. 

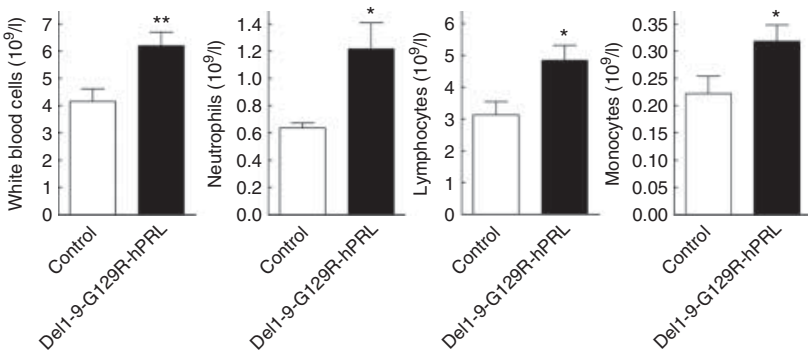

\section{Figure 6}

Leukocyte concentrations in the blood of Del1-9-G129R-hPRL transgenic bone marrow-transplanted LDL receptor knockout mice and their non-transgenic littermate-transplanted controls. Blood samples were collected after 12 weeks of WTD feeding. Data are expressed as means \pm S.E.M. of 11-12 mice per group. ${ }^{*} P<0.05,{ }^{*} P<0.01$ ( $t$-test).

abolition of prolactin receptor signaling failed to affect immune cell development or function, which may reflect cytokine receptor signaling redundancy (Bouchard et al. 1999), many studies have shown that (over-)stimulation of PRLR signaling impacted on the immune response. For example, hyperprolactinemia exacerbates Salmonella enterica infection-related pro-inflammatory cytokine secretion in BALB/c mice (Meli et al. 2003). Furthermore, expressions of co-stimulatory molecules and cytokine secretion by splenic dendritic cells of BALB/c mice are induced by prolactin (Yang et al. 2006). Moreover, persistently elevated serum prolactin levels interfere with $\mathrm{B}$ cell tolerance induction in BALB/c mice (Saha et al. 2009). However, it appears that the impact of the prolactin/prolactin receptor axis on immune function is highly dependent on the genetic background. Accordingly, high levels of prolactin underlie a break in B cell tolerance and cause a lupus-like phenotype in $R 4 A-\gamma 2 b$ BALB/c mice but not in R4A- $\gamma 2 \mathrm{~b}$ C57BL/6 mice (Peeva et al. 2003). In our study, while the Ldlr knockout recipients were fully (greater than ten times) backcrossed onto the C57BL/6 background, Del1-9-G129R-hPRL bone marrow donors were on a mixed background (BALB/ $\mathrm{c} / \mathrm{C} 57 \mathrm{BL} / 6)$. However, given the fact that we used nontransgenic littermates as control donors, a difference in genetic background can be ruled out as the reason for the unanticipated Del1-9-G129R-hPRL-induced increase in leukocyte numbers.

Most evidences regarding the pro-inflammatory effect of prolactin are derived from experimental settings in which the effect of relatively high levels of prolactin (hyperprolactinemia) on immune function has been evaluated. Importantly, our prolactin receptor antagonist studies were carried out in a normoprolactinemic setting.
As Del-1-9-G129R-hPRL was shown to be devoid of any residual agonism toward the mouse prolactin receptor (Bernichtein et al. 2003, Rouet et al. 2010), any increase in PRL-like activity in transplanted mice is unlikely. It can therefore be anticipated that a u-shaped relationship between prolactin levels/action and inflammation status may exist. However, additional studies in other experimental inflammation-related, i.e., endotoxemia and sepsis, mouse models are warranted to prove such a relation and suggest the potential relevance for the application of prolactin receptor antagonists in the human situation.

In conclusion, our studies show that prolactin receptor signaling inhibition uncouples the plasma atherogenic index from atherosclerosis susceptibility in Ldlr knockout mice. Despite an associated decrease in VLDL/LDL cholesterol levels, application of the prolactin receptor antagonist Del1-9-G129R-hPRL does not alter the susceptibility for atherosclerotic lesion development probably due to the parallel increase in circulating leukocyte concentrations.

\section{Declaration of interest}

All authors have nothing to disclose. Our grant suppliers, the Dutch Heart Foundation and the Netherlands Organization for Scientific Research, are non-commercial funding agencies and were not involved in the acquisition and interpretation of the data or the decision to publish the work.

\section{Funding}

This work was supported by grants 2008 T070 and 2012T080 from the Dutch Heart Foundation awarded to $\mathrm{M} \mathrm{H}$, grant 91813603 from the Netherlands Organization for Scientific Research awarded to $M V E$, and recurrent Inserm funding to Vincent Goffin's Laboratory. M V E is an established investigator of the Dutch Heart Foundation (grant number 2007T056).

\section{Author contribution statement}

$R \mathrm{~J}$ van der $\mathrm{S}, \mathrm{T}$ van den $\mathrm{A}$, and $\mathrm{F} B$ executed the experiments and performed data analysis. A Q R, M T T, and M V E supplied essential scientific input into the project. $\mathrm{V} \mathrm{G}$ and $\mathrm{M} \mathrm{H}$ initiated and supervised the experimental work and wrote the manuscript.

\section{References}

Arslan MS, Topaloglu O, Sahin M, Tutal E, Gungunes A, Cakir E, Ozturk IU, Karbek B, Ucan B, Ginis Z et al. 2014 Preclinical atherosclerosis in patients with prolactinoma. Endocrine Practice 20 447-451. (doi:10.4158/EP13173.OR)

Berinder K, Nyström T, Höybye C, Hall K \& Hulting AL 2011 Insulin sensitivity and lipid profile in prolactinoma patients before and after normalization of prolactin by dopamine agonist therapy. Pituitary 14 199-207. (doi:10.1007/s11102-010-0277-9)

Bernichtein S, Kayser C, Dillner K, Moulin S, Kopchick JJ, Martial JA, Norstedt G, Isaksson O, Kelly PA \& Goffin V 2003 Development of pure 
prolactin receptor antagonists. Journal of Biological Chemistry $\mathbf{2 7 8}$ 35988-35999. (doi:10.1074/jbc.M305687200)

Boring L, Gosling J, Cleary M \& Charo IF 1998 Decreased lesion formation in CCR2 - / - mice reveals a role for chemokines in the initiation of atherosclerosis. Nature 394 894-897. (doi:10.1038/29788)

Bouchard B, Ormandy CJ, Di Santo JP \& Kelly PA 1999 Immune system development and function in prolactin receptor-deficient mice. Journal of Immunology 163 576-582.

Chang LL, Lo MJ, Kan SF, Huang WJ, Chen JJ, Kau MM, Wang JL, Lin H, Tsai SC, Chiao YC et al. 1999 Direct effects of prolactin on corticosterone release by zona fasciculata-reticularis cells from male rats. Journal of Cellular Biochemistry 73 563-572. (doi:10.1002/(SICI)10974644(19990615)73:4<563::AID-JCB14>3.0.CO;2-G)

Cholesterol Treatment Trialists' (CTT) Collaborators. Mihaylova B, Emberson J, Blackwell L, Keech A, Simes J, Barnes EH, Voysey M, Gray A, Collins R et al. 2012 The effects of lowering LDL cholesterol with statin therapy in people at low risk of vascular disease: meta-analysis of individual data from 27 randomised trials. Lancet 380 581-590. (doi:10.1016/S0140-6736(12)62027-3)

Chomczynski P \& Sacchi N 1987 Single-step method of RNA isolation by acid guanidinium thiocyanate-phenol-chloroform extraction. Analytical Biochemistry 162 156-159. (doi:10.1016/0003-2697(87)90021-2)

Dardenne M, de Moraes Mdo C, Kelly PA \& Gagnerault MC 1994 Prolactin receptor expression in human hematopoietic tissues analyzed by flow cytofluorometry. Endocrinology 134 2108-2114.

Dugan AL, Schwemberger S, Noel GJ, Babcock GF, Ogle CK, Buckley DJ, Horseman ND \& Gregerson KA 2007 Stress and prolactin effects on bone marrow myeloid cells, serum chemokine and serum glucocorticoid levels in mice. Neuroimmunomodulation 14 287-296. (doi:10.1159/ 000117810)

Fahy U, Hopton MI, Hartog M, Bolton CH \& Hull MG 1999 The lipoprotein profile of women with hyperprolactinaemic amenorrhoea. Human Reproduction 14 285-287. (doi:10.1093/humrep/14.2.285)

Georgiopoulos GA, Stamatelopoulos KS, Lambrinoudaki I, Lykka M, Kyrkou K, Rizos D, Creatsa M, Christodoulakos G, Alevizaki M, Sfikakis PP et al. 2009 Prolactin and preclinical atherosclerosis in menopausal women with cardiovascular risk factors. Hypertension 54 98-105. (doi:10.1161/HYPERTENSIONAHA.109.132100)

Gu L, Okada Y, Clinton SK, Gerard C, Sukhova GK, Libby P \& Rollins BJ 1998 Absence of monocyte chemoattractant protein-1 reduces atherosclerosis in low density lipoprotein receptor-deficient mice. Molecular Cell 2 275-281. (doi:10.1016/S1097-2765(00)80139-2)

Haring R, Friedrich N, Völzke H, Vasan RS, Felix SB, Dörr M, Meyer Zu Schwabedissen HE, Nauck M \& Wallaschofski H 2014 Positive association of serum prolactin concentrations with all-cause and cardiovascular mortality. European Heart Journal 35 1215-1221. (doi:10.1093/eurheartj/ehs233)

Hoekstra M, Kruijt JK, Van Eck M \& Van Berkel TJ 2003 Specific gene expression of ATP-binding cassette transporters and nuclear hormone receptors in rat liver parenchymal, endothelial, and Kupffer cells. Journal of Biological Chemistry 278 25448-25453. (doi:10.1074/jbc. M301189200)

Hoekstra M, Frodermann V, van den Aardweg T, van der Sluis RJ \& Kuiper J 2013 Leukocytosis and enhanced susceptibility to endotoxemia but not atherosclerosis in adrenalectomized APOE knockout mice. PLoS ONE 8 e80441. (doi:10.1371/journal.pone.0080441)

Hou L, Lloyd-Jones DM, Ning H, Huffman MD, Fornage M, He K, Zhang X, Jacobs DR, Goff DC, Sidney S et al. 2013 White blood cell count in young adulthood and coronary artery calcification in early middle age: coronary artery risk development in young adults (CARDIA) study. European Journal of Epidemiology 28 735-742. (doi:10.1007/s10654013-9842-7)

Ishibashi S, Brown MS, Goldstein JL, Gerard RD, Hammer RE \& Herz J 1993 Hypercholesterolemia in low density lipoprotein receptor knockout mice and its reversal by adenovirus-mediated gene delivery. Journal of Clinical Investigation 92 883-893. (doi:10.1172/JCI116663)

http://joe.endocrinology-journals.org DOI: $10.1530 / J O E-14-0343$
(C) 2014 Society for Endocrinology Printed in Great Britain
Jaroenporn S, Nagaoka K, Ohta R, Watanabe G \& Taya K 2007 Direct effects of prolactin on adrenal steroid release in male Hatano high-avoidance (HAA) rats may be mediated through Janus kinase 2 (Jak2) activity. Journal of Reproduction and Development 53 887-893. (doi:10.1262/ jrd.18174)

Jee SH, Park JY, Kim HS, Lee TY \& Samet JM 2005 White blood cell count and risk for all-cause, cardiovascular, and cancer mortality in a cohort of Koreans. American Journal of Epidemiology 162 1062-1069. (doi:10.1093/aje/kwi326)

Jiang XB, Li CL, He DS, Mao ZG, Liu DH, Fan X, Hu B, Zhu YH \& Wang HJ 2014 Increased carotid intima media thickness is associated with prolactin levels in subjects with untreated prolactinoma: a pilot study. Pituitary 17 232-239. (doi:10.1007/s11102-013-0495-z)

Li Z, Yu C, Han Y, Ren H, Shi W, Fu C, He D, Huang L, Yang C, Wang X et al. 2008 Inhibitory effect of D1-like and D3 dopamine receptors on norepinephrine-induced proliferation in vascular smooth muscle cells. American Journal of Physiology. Heart and Circulatory Physiology 294 H2761-H2768.

Lo MJ \& Wang PS 2003 Relative and combined effects of estradiol and prolactin on corticosterone secretion in ovariectomized rats. Chinese Journal of Physiology 46 103-109.

McKenna F, McLaughlin PJ, Lewis BJ, Sibbring GC, Cummerson JA, BowenJones D \& Moots RJ 2002 Dopamine receptor expression on human T- and B-lymphocytes, monocytes, neutrophils, eosinophils and NK cells: a flow cytometric study. Journal of Neuroimmunology 132 34-40. (doi:10.1016/S0165-5728(02)00280-1)

Meli R, Bentivoglio C, Nuzzo I, Mattace Raso G, Galdiero E, Galdiero M, Di Carlo R \& Carratelli CR 2003 Th1-Th2 response in hyperprolactinemic mice infected with Salmonella enterica serovar Typhimurium. European Cytokine Network 14 186-191.

Ni W, Egashira K, Kitamoto S, Kataoka C, Koyanagi M, Inoue S, Imaizumi K, Akiyama C, Nishida KI \& Takeshita A 2001 New anti-monocyte chemoattractant protein-1 gene therapy attenuates atherosclerosis in apolipoprotein E-knockout mice. Circulation 103 2096-2101. (doi:10.1161/01.CIR.103.16.2096)

Peeva E, Michael D, Cleary J, Rice J, Chen X \& Diamond B 2003 Prolactin modulates the naive B cell repertoire. Journal of Clinical Investigation 111 275-283. (doi:10.1172/JCI200316530)

Reuwer AQ, van Eijk M, Houttuijn-Bloemendaal FM, van der Loos CM, Claessen N, Teeling P, Kastelein JJ, Hamann J, Goffin V, von der Thüsen $\mathrm{JH}$ et al. 2011 The prolactin receptor is expressed in macrophages within human carotid atherosclerotic plaques: a role for prolactin in atherogenesis? Journal of Endocrinology 208 107-117. (doi:10.1677/ JOE-10-0076)

Rouet V, Bogorad RL, Kayser C, Kessal K, Genestie C, Bardier A, Grattan DR, Kelder B, Kopchick JJ, Kelly PA et al. 2010 Local prolactin is a target to prevent expansion of basal/stem cells in prostate tumors. PNAS $\mathbf{1 0 7}$ 15199-15204. (doi:10.1073/pnas.0911651107)

Saha S, Gonzalez J, Rosenfeld G, Keiser H \& Peeva E 2009 Prolactin alters the mechanisms of B cell tolerance induction. Arthritis and Rheumatism 60 1743-1752. (doi:10.1002/art.24500)

van der Sluis RJ, van Puijvelde GH, Van Berkel TJ \& Hoekstra M 2012 Adrenalectomy stimulates the formation of initial atherosclerotic lesions: reversal by adrenal transplantation. Atherosclerosis 221 76-83. (doi:10.1016/j.atherosclerosis.2011.12.022)

Tong PC, Lee KF, So WY, Ng MH, Chan WB, Lo MK, Chan NN \& Chan JC 2004 White blood cell count is associated with macro- and microvascular complications in Chinese patients with type 2 diabetes. Diabetes Care 27 216-222. (doi:10.2337/diacare.27.1.216)

Touraine P \& Kelly PA 1995 Expression of the short and long forms of the prolactin receptor in murine lymphoid tissues. Recent Progress in Hormone Research $\mathbf{5 0} 423-428$.

Twig G, Afek A, Shamiss A, Derazne E, Tzur D, Gordon B \& Tirosh A 2012 White blood cell count and the risk for coronary artery disease in young adults. PLoS ONE 7 e47183. (doi:10.1371/journal.pone.0047183) 
VanderLaan PA, Reardon CA, Thisted RA \& Getz GS 2009 VLDL best predicts aortic root atherosclerosis in LDL receptor deficient mice. Journal of Lipid Research 50 376-385. (doi:10.1194/jlr.M800284-JLR200)

Van Eck M, Herijgers N, Yates J, Pearce NJ, Hoogerbrugge PM, Groot PH \& Van Berkel TJ 1997 Bone marrow transplantation in apolipoprotein E-deficient mice. Effect of ApoE gene dosage on serum lipid concentrations, (beta)VLDL catabolism, and atherosclerosis. Arteriosclerosis, Thrombosis, and Vascular Biology 17 3117-3126. (doi:10.1161/01.ATV.17.11.3117)

Van Eck M, Ye D, Hildebrand RB, Kar Kruijt J, de Haan W, Hoekstra M, Rensen PC, Ehnholm C, Jauhiainen M \& Van Berkel TJ 2007 Important role for bone marrow-derived cholesteryl ester transfer protein in lipoprotein cholesterol redistribution and atherosclerotic lesion development in LDL receptor knockout mice. Circulation Research 100 678-685. (doi:10.1161/01.RES.0000260202.79927.4f)

Vikstedt R, Ye D, Metso J, Hildebrand RB, Van Berkel TJ, Ehnholm C, Jauhiainen M \& Van Eck M 2007 Macrophage phospholipid transfer protein contributes significantly to total plasma phospholipid transfer activity and its deficiency leads to diminished atherosclerotic lesion development. Arteriosclerosis, Thrombosis, and Vascular Biology $\mathbf{2 7}$ 578-586. (doi:10.1161/01.ATV.0000254815.49414.be)

Wu ZB, Yu CJ, Su ZP, Zhuge QC, Wu JS \& Zheng WM 2006 Bromocriptine treatment of invasive giant prolactinomas involving the cavernous sinus: results of a long-term follow up. Journal of Neurosurgery $\mathbf{1 0 4}$ 54-61. (doi:10.3171/jns.2006.104.1.54)

Yang L, Hu Y, Li X, Zhao J \& Hou Y 2006 Prolactin modulates the functions of murine spleen CD11c-positive dendritic cells. International Immunopharmacology 6 1478-1486. (doi:10.1016/j.intimp.2006.05.001)

Yarman S, Kurtulmus N \& Bilge A 2012 Optimal effective doses of cabergoline and bromocriptine and valvular leasions in men with prolactinomas. Neuro Endocrinology Letters 33 340-346.

Zeng C, Wang D, Yang Z, Wang Z, Asico LD, Wilcox CS, Eisner GM, Welch WJ, Felder RA \& Jose PA 2004 Dopamine D1 receptor augmentation of D3 receptor action in rat aortic or mesenteric vascular smooth muscles. Hypertension 43 673-679. (doi:10.1161/01.HYP.0000118958.27649.6f)

Received in final form 18 July 2014

Accepted 24 July 2014

Accepted Preprint published online 25 July 2014 http://joe.endocrinology-journals.org DOI: $10.1530 / \mathrm{JOE}-14-0343$
(C) 2014 Society for Endocrinology Printed in Great Britain
Published by Bioscientifica Ltd. 